\title{
ARTICLE
}

Received 4 Apr 2016 | Accepted 23 Aug 2016 | Published 30 Sep $2016 \quad$ DOl: 10.1038/ncomms12984 OPEN

\section{Chemotaxis towards autoinducer 2 mediates autoaggregation in Escherichia coli}

\author{
Leanid Laganenka', Remy Colin ${ }^{1} \&$ Victor Sourjik ${ }^{1}$
}

Bacteria communicate by producing and sensing extracellular signal molecules called autoinducers. Such intercellular signalling, known as quorum sensing, allows bacteria to coordinate and synchronize behavioural responses at high cell densities. Autoinducer 2 (Al-2) is the only known quorum-sensing molecule produced by Escherichia coli but its physiological role remains elusive, although it is known to regulate biofilm formation and virulence in other bacterial species. Here we show that chemotaxis towards self-produced Al-2 can mediate collective behaviour-autoaggregation-of E. coli. Autoaggregation requires motility and is strongly enhanced by chemotaxis to Al-2 at physiological cell densities. These effects are observed regardless whether cell-cell interactions under particular growth conditions are mediated by the major E. coli adhesin (antigen 43) or by curli fibres. Furthermore, Al-2-dependent autoaggregation enhances bacterial stress resistance and promotes biofilm formation.

\footnotetext{
${ }^{1}$ Max Planck Institute for Terrestrial Microbiology and LOEWE Center for Synthetic Microbiology (SYNMIKRO), Karl-von-Frisch Strasse 16, 35043 Marburg, Germany. Correspondence and requests for materials should be addressed to V.S. (email: victor.sourjik@synmikro.mpi-marburg.mpg.de).
} 
$t$ is well established that under many natural environmental conditions bacteria prefer to exist as multicellular structures, such as surface-attached biofilms or freely floating aggregates. Within these structures cells are protected from various stress factors such as exposure to ultraviolet light, acids, detergents or antimicrobial agents ${ }^{1,2}$.

The Gram-negative bacterium Escherichia coli is one of the model organisms for studying both cell aggregation and biofilm formation. Autoaggregation in E. coli is observed as emergence of microscopic cell clumps that can further lead to macroscopic flocculation and settling of cells in static liquid cultures ${ }^{3}$. A major determinant of autoaggregation in E. coli is antigen 43 (Ag43), the abundant outer membrane protein that belongs to the autotransporter family and is secreted via the type $\mathrm{V}$ secretion system $^{4}$. During autoaggregation, Ag43 $\alpha$-subunits of adjacent cells interact in a head-to-tail conformation resulting in dimer formation ${ }^{5}$. While Ag43 is the only known surface factor implicated in autoaggregation of exponentially growing non-pathogenic E. coli, pathogenic strains can also aggregate via fimbriae or pili $^{6-8}$. Moreover, at lower growth temperatures (below $30^{\circ} \mathrm{C}$ ) and in the later growth phase, formation of cellular aggregates can also be mediated by interactions of curli fibres, a major proteinaceous component of $E$. coli biofilm matrix ${ }^{9-12}$.

Expression of Ag43 is a classic example of phase variation, where cells in a clonal population can be either in an $\mathrm{ON}$ state (expressing Ag43) or in an OFF state. Ag43 phase variation results from binding competition between the repressor OxyR and Dam methyltransferase (methylase) to the regulatory region of agn43 (alternatively called $f l u$ ). Deletion of $o x y R$ leads to a locked-ON state, whereas deletion of dam leads to a locked-OFF state $^{13}$.

Although bacterial autoaggregation is normally thought of as a passive process, during the mid- to late exponential phase of growth when aggregation becomes apparent E. coli cells are highly motile and chemotactic, that is, able to follow gradients of nutrients and other environmental stimuli ${ }^{14}$. These chemotactic stimuli are detected by transmembrane chemoreceptors that regulate activity of the cytoplasmic histidine kinase CheA and subsequent phosphorylation of the response regulator CheY. Phosphorylated CheY binds to flagellar motors and induces a switch from the default counterclockwise to clockwise rotation, promoting cell tumbling. Increased binding of chemoattractants to the sensory domain of receptors-which can be either direct or mediated by periplasmic binding proteins-results in inhibition of the autophosphorylation activity of CheA and decrease in the level of phosphorylated CheY, causing smooth swimming.

Chemotaxis to self-secreted attractants is well known to promote aggregation of eukaryotic organisms, such as social amoebae ${ }^{15}$. It was thus speculated that chemotaxis-dependent aggregation might also exist in bacteria ${ }^{16}$, but direct evidence for such behaviour is still missing. In a porous medium or in a microfluidic channel, E. coli can indeed form large dynamic clusters where thousands of cells are kept together solely through chemotactic self-attraction ${ }^{17-21}$. However, this behaviour only occurs under specific conditions when $E$. coli secretes high levels of amino acids that act as attractants, and its physiological significance remained unclear. Besides E. coli, regulation of motility by the chemotaxis pathway has been shown to affect autoaggregation (clumping) of Azospirillum brasiliense, but this regulation is inhibitory and chemotaxis itself is not required for aggregation $^{22}$.

In this study, we provide evidence for the involvement of motility and chemotaxis in the Ag43-dependent aggregation of E. coli. Our results suggest that aggregation should be seen as an active process that requires not only specific adhesins but also swimming to promote random intercellular collisions and subsequent chemotactic response to gradients of self-produced attractant. We further show that this self-attraction is mediated by the quorum-sensing molecule autoinducer-2 (AI-2), the only quorum-sensing signal described for E. coli. Chemotaxis to AI-2 similarly promotes aggregative behaviour mediated by curli fibres in cells grown at low temperature to the early stationary phase. Our results demonstrate that such chemotaxis-driven aggregation enhances AI-2-mediated signalling, biofilm formation and stress resistance.

\section{Results}

Aggregation of $\boldsymbol{E}$. coli depends on motility and chemotaxis. We first investigated aggregation of E. coli strain W3110 (RpoS $\left.{ }^{+}\right)^{12}$ grown at $37^{\circ} \mathrm{C}$ to a mid-exponential growth phase. Consistent with previous studies performed for other E. coli K-12 strains ${ }^{8}$, under these conditions the high-density $\left(\mathrm{OD}_{600}\right.$ of 2.0) culture of W3110 showed reproducible aggregation that was dependent on Ag43 (Supplementary Fig. 1) but not on curli or on other biofilm matrix components, poly-beta-1,6- $N$-acetyl-D-glucosamine and colanic acid (Supplementary Fig. 2). This result confirms that a large fraction of W3110 cells is in the ON state of agn43 expression under our conditions. Nevertheless, to avoid potential complexity associated with the phase variation of agn 43 expression between and within individual cultures ${ }^{23}$, we subsequently used overexpression of the Dam methyltransferase to lock our strains in the ON state (Supplementary Fig. 3). The $\mathrm{Dam}^{+}+$wild-type strain aggregated even more efficiently than the original W3110 wild type (compare Fig. 1a and Supplementary Fig. 1). Aggregation was also dependent on density of the cell culture, being negligible below $\mathrm{OD}_{600}$ of 0.25 , relatively constant in the $\mathrm{OD}_{600}$ range between 0.5 and 2.0, and further increasing at $\mathrm{OD}_{600}$ of 6.0 (Fig. 1a and Supplementary Fig. 4).

Notably, we observed that aggregation was completely abolished not only by deletion of agn 43 ( $\Delta$ flu) (Fig. 1b) but also on deletion of $\mathrm{fliC}$ that encodes flagellin (Fig. $1 \mathrm{c}$ and Supplementary Fig. 1). A similar defect was observed for a $\Delta$ motA mutant that lacks a major component of the flagellar motor and has paralysed flagella (Fig. 1d). Aggregation of $\Delta f l u$, $\triangle f l i C$ and $\Delta m o t A$ strains could not be restored even at very high cell density, meaning that both Ag43 and flagella-driven motility are strictly required for this process.

Furthermore, we observed that aggregation was severely affected in the non-chemotactic (but motile) $\Delta$ cheY mutant (Fig. 1e and Supplementary Fig. 1). In contrast to motilitydeficient strains $\Delta$ cheY cells still formed small aggregates. However, at $\mathrm{OD}_{600}=1.0$ these aggregates did not reach the size of the wild-type structures (Fig. 1f). This requirement of chemotaxis for aggregation was even more pronounced at lower cell densities, but it was largely alleviated at very high cell density when aggregation of $\Delta c h e Y$ and wild-type cells became comparable (Fig. 1e and Supplementary Fig. 4). We thus concluded that while chemotaxis (as opposed to motility) is not absolutely essential for aggregation, it strongly enhances aggregation at lower cell densities, likely by mediating attraction of individual motile cells towards aggregates. We further observed that aggregation requires chemoreceptor Tsr, which is highly abundant in exponentially growing $E$. coli cells ${ }^{24}$, whereas the deletion of Tar, another major chemoreceptor, had a milder effect (Fig. 1f and Supplementary Fig. 1).

Chemotaxis to AI-2 enhances aggregation. The involvement of Tsr in aggregation was particularly interesting, since this receptor has been previously shown to mediate chemotactic response to AI-2, a universal quorum-sensing molecule that can be produced 
a
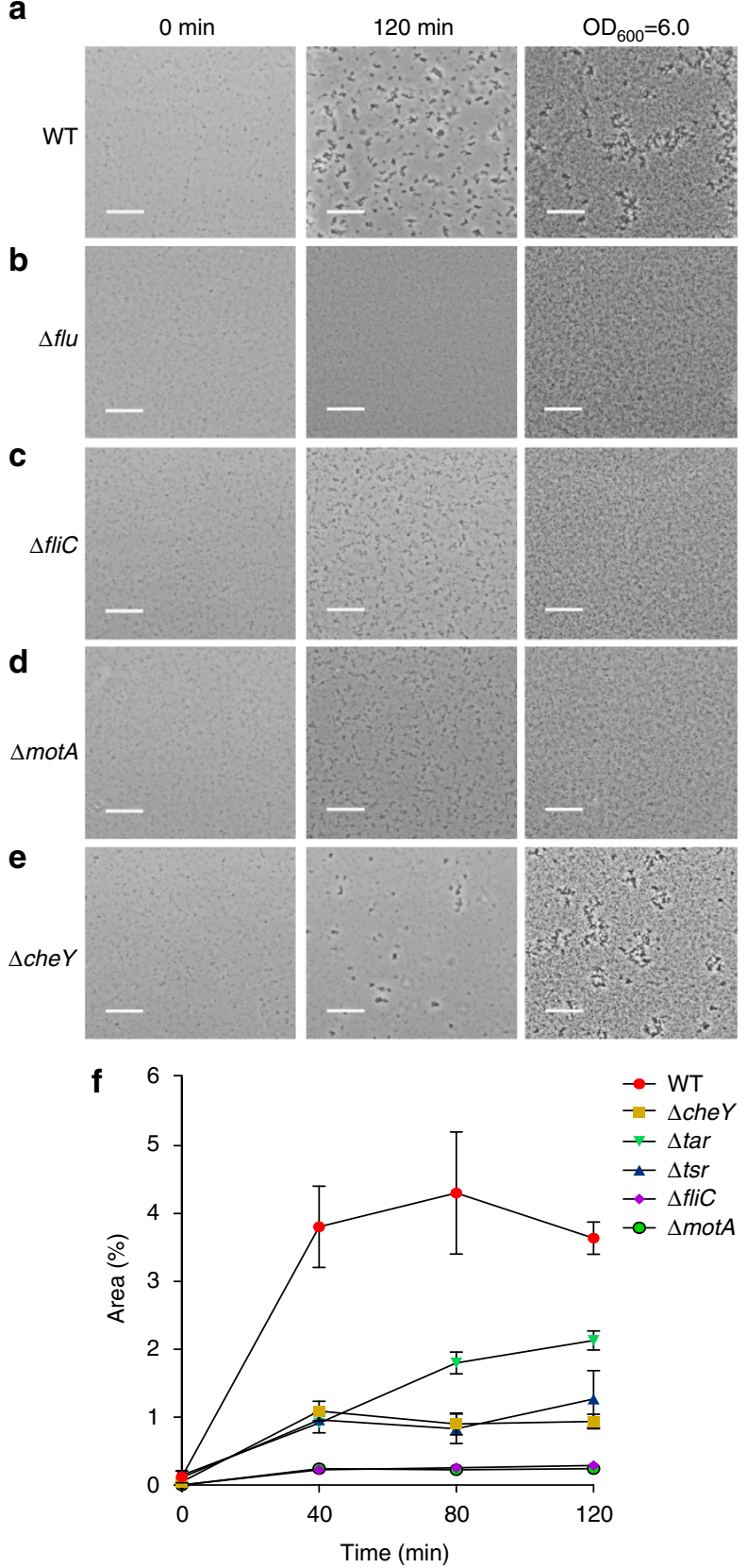

Figure 1 | Swimming motility and chemotaxis are required for

autoaggregation. (a-e) Aggregation of the wild-type E. coli W3110 (a), and its $\Delta f l u(\mathbf{b}), \Delta f l i C(\mathbf{c}), \Delta \operatorname{mot} A(\mathbf{d})$ and $\Delta$ cheY $(\mathbf{e})$ knockouts grown to $\mathrm{OD}_{600}$ of 0.6 at $37^{\circ} \mathrm{C}$. For aggregation experiments, cells were resuspended in fresh TB medium to $\mathrm{OD}_{600}$ of 1.0 (two left panels) or 6.0 (right panel), and aggregation was assayed at room temperature in channels using microscopy as described in Methods. Aggregation at $\mathrm{OD}_{600}$ of 6.0 is shown at $120 \mathrm{~min}$. Scale bars, $20 \mu \mathrm{m}$. (f) Quantification of the area occupied by aggregates in microscopy images for the wild type and indicated mutants. Error bars indicate s.d. of three independent replicates.

and recognized by many bacteria ${ }^{25,26}$. AI-2 is a by-product of the activated methyl cycle, required for recycling of $S$-adenosyl-Lmethionine. In E. coli, AI-2 is initially produced by the enzyme LuxS as (S)-4,5-dihydroxy-2,3-pentandione (DPD) and later undergoes spontaneous cyclization. E. coli possesses a specific ATP-binding cassette transporter for AI-2 uptake, which includes the periplasmic binding protein LsrB, the a

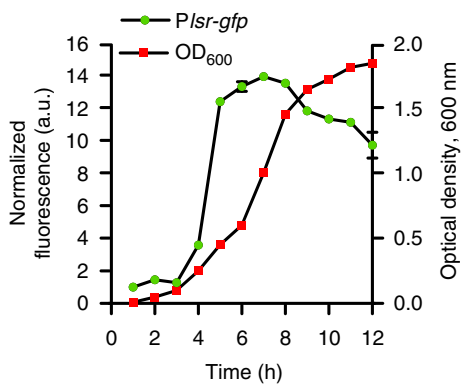

b

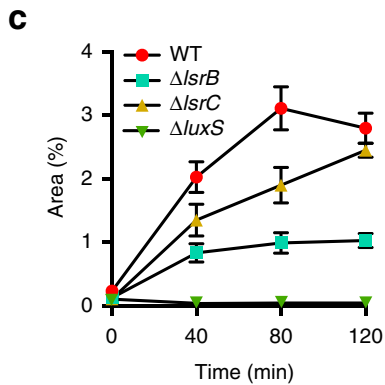

d

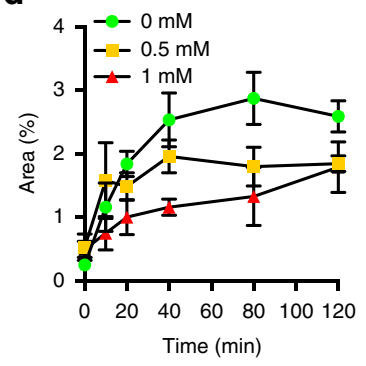

Figure 2 | Autoaggregation depends on production and sensing of

autoinducer 2. (a) Activity of the Isr promoter reporting Al-2 levels during growth of the wild-type population as a function of the growth stage of E. coli culture. (b) Aggregation of the wild type at different stages of growth, assayed as in Fig. 1. (c) Aggregation of strains defective in production $(\Delta / u x S)$, sensing and import $(\Delta / s r B)$ or only import $(\Delta / s r C)$ of $\mathrm{Al}-2$.

(d) Effects of indicated concentrations of added DPD on aggregation of the wild-type cells. Error bars in all panels indicate s.d. of three independent replicates.

cytoplasmic ATP-binding protein LsrA, as well as two membrane proteins, LsrC and LsrD, that form the transport channel ${ }^{25}$. The imported AI-2 undergoes phosphorylation by LsrK and then binds to and activates LsrR, which leads to derepression of the $l s r$ operon and possibly other genes ${ }^{25}$. Besides its function in transport, AI-2-bound LsrB was proposed to interact with the sensory domain of Tsr, thereby eliciting a chemotactic response ${ }^{27}$.

E. coli is known to primarily produce and secrete AI-2 during the mid- to late exponential growth phase ${ }^{25}$ (Fig. 2a), which is seemingly consistent with the growth phase dependence of autoaggregation (Fig. 2b). Together with the requirement of Tsr for aggregation, this indicated that AI- 2 might be the aggregationpromoting chemotactic signal. This hypothesis was supported by strongly reduced aggregation of $\Delta l u x S$ and $\Delta l s r B$ mutants that are impaired in production and perception of AI-2, respectively (Fig. 2c, Supplementary Figs 1 and 5 and Supplementary Fig. 5). Although the deletion of luxS also resulted in decreased motility (Supplementary Fig. 5a) thus complicating data interpretation, $\Delta l s r B$ showed normal motility and chemotaxis towards amino acids while its aggregation was reduced to the level of $\Delta$ cheY strain. This defect of $\Delta l s r B$ strain in aggregation was apparently due to its deficiency in the sensing of AI-2 and not because of the deficient uptake, as deletion of $l s r C$ that similarly abolishes the AI-2 uptake led to only a minor reduction of aggregation (Fig. 2c). Consistent with the involvement of AI-2 signalling, addition of synthetic DPD/AI-2 (that is, DPD that spontaneously converted to AI-2) to the wild-type culture reduced aggregation in a dose-dependent manner (Fig. 2d).

To directly confirm that AI-2 is a specific LsrB-dependent chemoattractant for $E$. coli $i^{27}$, we studied $E$. coli behaviour in 
microfluidic gradients of the synthetic DPD/AI-2, using a non-metabolizable attractant $\alpha$-D,L-methylaspartic acid (MeAsp) as a positive control (Supplementary Fig. 6a,b). The movement of wild-type cells showed a pronounced chemotactic bias up the $0-10 \mu \mathrm{M}$ gradient of DPD/AI-2 (Supplementary Fig. 6c), comparable to the bias observed for the $0-200 \mu \mathrm{M}$ gradient of MeAsp. As expected, $\Delta l s r B$ strain showed no chemotaxis to AI-2. Notably, wild-type cells were no longer able to follow the same gradient of DPD/AI-2 above the background of $200 \mu \mathrm{M}$. This is consistent with a narrow dynamic range of attractant concentrations that can be sensed via a periplasmic binding $\operatorname{protein}^{28}$, due to saturation of the sensor at high background stimulation. Importantly, no apparent effect of even high background concentration of AI-2 on swimming speed or chemotaxis to MeAsp was observed (Supplementary Fig. 6c,d). Taken together, these results strongly suggest that AI-2 acts as a specific chemoattractant during autoaggregation of E. coli.

Chemotaxis governs kinetics of aggregation and disaggregation. To better understand the dynamics of autoaggregation and its dependence on AI-2 chemotaxis, we followed its early stage with high time resolution and at lower cell density $\left(\mathrm{OD}_{600}=0.5\right)$ (Fig. 3a-c, and Supplementary Movies 1 and 2). We observed that the aggregation of the wild-type cells proceeds very rapidly, with $\sim 50 \%$ of cells being incorporated into the aggregates already during the first $5 \mathrm{~min}$ of observation $(\sim 8 \mathrm{~min}$ after the cells were loaded into the channel; Fig. 3a,b). During this phase, both the number (Fig. 3b) and size of aggregates (Fig. 3c) increased. Subsequently, the aggregation slowed down, reaching a peak at about $1 \mathrm{~h}$, when the majority of cells became incorporated into the aggregates (Supplementary Movie 3). Nevertheless, individual aggregates remained highly dynamic in their size (Supplementary Fig. 7, and Supplementary Movies 1 and 3). Such dynamics demonstrates reversibility of cell incorporation into Ag43-mediated aggregates, which is consistent with a relatively low strength of interactions mediated by Ag43 (ref. 5).

The rate of aggregation was significantly lower for $\Delta c h e Y$ and $\Delta l s r B$ strains (Fig. 3a-c and Supplementary Movie 2), with both the number and the size of aggregates increasing slower than in the wild type. Notably, this difference in the aggregate size and number was already observed at the early stage of aggregation, when the size of aggregates was below $50 \mu \mathrm{m}$. The rate of aggregation and particularly the number of aggregates were also moderately decreased in $\Delta l s r C$ cells that are deficient in AI-2 uptake, indicating that degradation might play a role in sharpening the AI-2 gradients.

Consistent with the reversible nature of cell association within aggregates, we further observed that after $2 \mathrm{~h}$ of incubation, aggregates formed by the wild-type cells began to disperse again (Fig. 3d), despite individual cells remaining highly motile (Supplementary Movie 4). Dispersal was not observed for $\Delta c h e Y$ or $\Delta l s r B$ aggregates, which remained at approximately constant size for over $5 \mathrm{~h}$, suggesting that it might be caused by the loss of chemotaxis towards aggregates. We hypothesized that this loss of chemotaxis is likely to be explained by excessive accumulation of $\mathrm{AI}-2$ in the medium during the experiment, which disables sensing of AI-2 gradients above this high background (Supplementary Fig. 6). Indeed, quantification of AI-2 in the cell-culture supernatant using transcriptional reporter showed that levels of AI-2 continued to rise at the onset of disaggregation (Fig. 3e and Supplementary Fig. 8). Consistent with an excess rather than depletion of AI-2 being a cause of disaggregation, similar dispersal kinetics was observed for the uptake-deficient $\Delta l s r C$ and wild-type cells (Fig. $3 \mathrm{~d}$ ).
Further supporting our hypothesis, addition of external synthetic DPD/AI-2 $(0.2 \mathrm{mM})$ even at later stages of autoaggregation greatly reduced the growth of the aggregates (Supplementary Fig. 9a,d), although the effect is presumably weakened by rapid consumption of AI-2. Similar inhibition and even moderate dispersal of the aggregates could be achieved by very high levels $(10 \mathrm{mM})$ of Tsr ligand L-serine, which are known to generally disable chemotaxis ${ }^{29}$. Even more pronounced dispersal effect was observed on incubation with 2-aminoisobutyric acid (AIbu), a less chemoattractive but non-metabolizable analogue of $\mathrm{L}$-serine $\mathrm{e}^{30}$, consistent with our assumption that degradation weakens the dispersal effects that are induced by added chemoattractants. Importantly, no dispersal was observed for $\Delta c h e Y$ and $\Delta l s r B$ aggregates on addition of AI-2 or other chemoattractants (Supplementary Fig. 9b,c,e,f), which confirms the key role of the chemotaxis inhibition in the dispersal process.

Aggregation promotes AI-2 signalling. We next explored the consequences of such chemotaxis-mediated autoaggregation on the AI-2-dependent transcriptional response. We speculated that high density of AI-2-secreting cells within aggregates might lead to more efficient response induction. Indeed, when cultures were incubated under conditions that enable aggregation, the induction of the $\mathrm{P}_{l s r}$-egfp reporter in the wild type-but not in the aggregation-deficient $\Delta f l u, \Delta c h e Y$ or $\Delta l s r B$ mutants-increased significantly during the first $40 \mathrm{~min}$ (Fig. 4a). This was likely explained by the increased local accumulation of AI-2 in the aggregates, because the wild-type strain overexpressing LuxS showed a steadily high level of $l s r$ operon expression.

Consistent with the proposed higher induction of the reporter in only a fraction of cells within aggregates, wild-type cells showed a broader distribution of the levels of reporter fluorescence than aggregation-deficient strains or than the wild-type overexpressing LuxS (Fig. 4b). To further confirm this interpretation, reporter fluorescence was imaged within aggregates and in non-aggregated planktonic cells using confocal microscopy. Aggregated cells had indeed higher level of $l s r$ operon induction (Fig. 4c), in contrast to the control cell expressing only egfp.

Aggregation enhances stress resistance and biofilm formation. Aggregation is known to enhance stress resistance of bacteria $^{2}$, including $E$. coli ${ }^{31}$. Consistent with these previous observations, wild-type cells that were treated with $\mathrm{H}_{2} \mathrm{O}_{2}$ had much higher rate of survival under conditions that favour aggregation (Fig. 5a). In contrast, no increase in survival was observed in non-aggregating $\Delta f l u$ cells, even on overexpression of LuxS. On the basis of these results, we conclude that the increased oxidative stress resistance is indeed mediated by physical protection of cells within aggregates rather than by the quorum-sensing signalling.

Although Ag43 is usually not considered as a major determinant of biofilm formation, the effect of $f l u$ deletion on surface-attached biofilms has been reported ${ }^{32}$. We thus tested possible involvement of the Ag43- and chemotaxis-dependent aggregation in biofilm formation. Indeed, crystal violet staining of surface-attached biofilms grown for $24 \mathrm{~h}$ at $37^{\circ} \mathrm{C}$ in microtitre plates revealed significant decrease in biofilm formation in $\Delta f l u$, $\Delta c h e Y$ and $\Delta l s r B$ strains (Fig. 5b). Microscopic observation of biofilms formed under such static conditions demonstrated that biofilms formed by $\Delta l s r B, \Delta c h e Y$ or $\Delta f l u$ cells were less structured than the wild-type biofilm (Fig. 5c). This was further confirmed by quantification of the microcolony volumes in biofilm images, which showed that the wild type formed significantly larger microcolonies than $\Delta c h e Y$ or $\Delta l s r B$, and $\Delta f l u$ formed no 

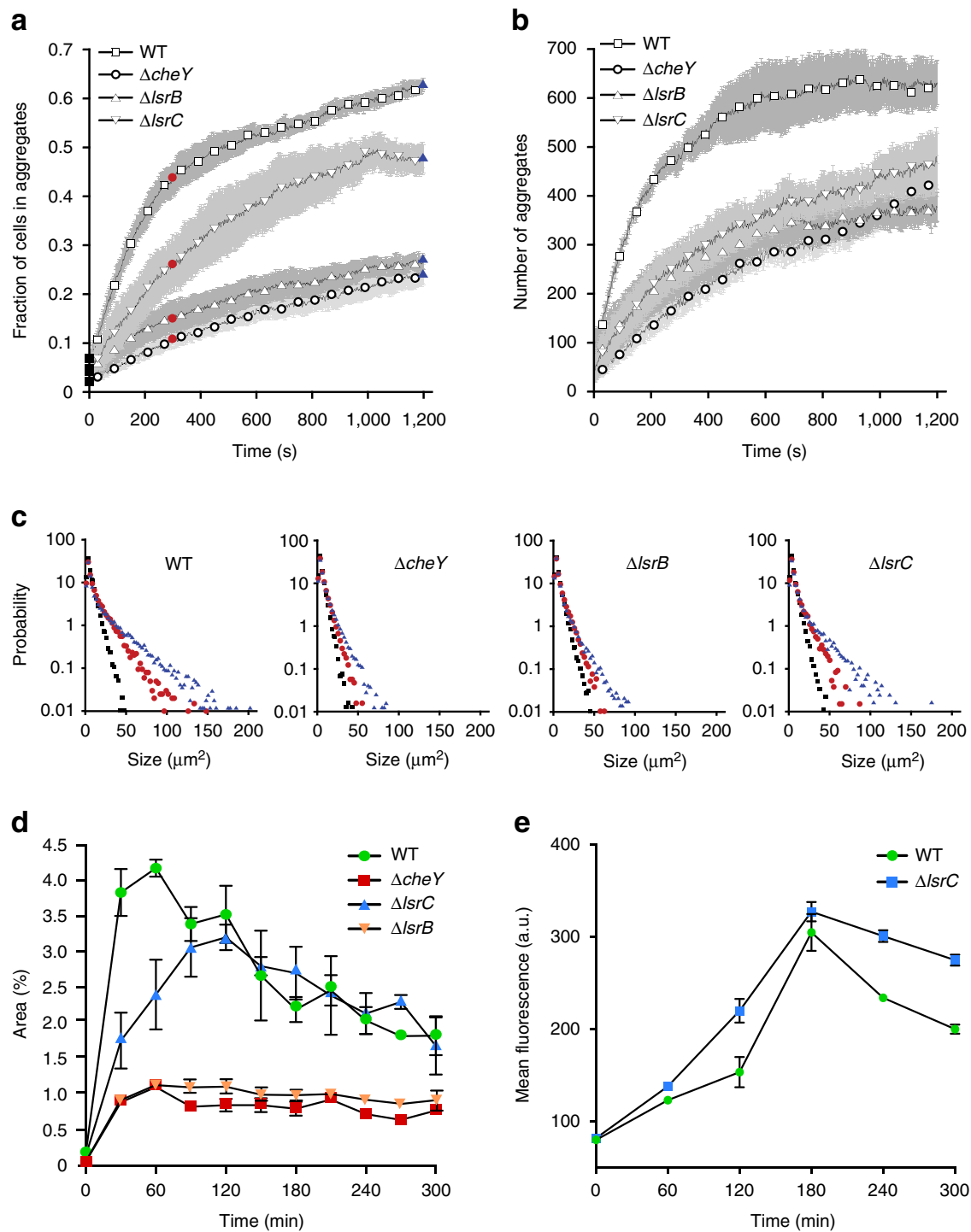

Figure 3 | Kinetics of initial aggregation and dispersal depend on Al-2. (a-c) Time dependence of the fraction of cells in aggregates (a), number of aggregates (b) and aggregate size (c). Distribution of aggregate sizes in $\mathbf{c}$ is shown at 0 (black squares), 5 (red circles) and 20 min (blue triangles), as indicated in a. Aggregation was assayed as in Fig. 1, except $\mathrm{OD}_{600}$ was adjusted to 0.5. (d,e) Dynamics of aggregation and dispersal for the wild-type, $\Delta c h e Y, \Delta / s r B$ and $\Delta / s r C$ strains over $5 \mathrm{~h}$ incubation (d) and corresponding levels of Al-2 activity in supernatants quantified using fluorescence reporter strain as described in Methods. Reporter fluorescence was measured using flow cytometry and expressed in arbitrary units (a.u.) of fluorescence. Aggregation was assayed as in Fig. 1. Error bars in all panels indicate s.d. of three independent replicates.

detectable microcolonies (Supplementary Fig. 10). Consistent with its greater importance for aggregation, deletion of Ag43 had a more pronounced effect on biofilm formation than the lack of AI-2 chemotaxis.

AI-2 chemotaxis enhances curli-mediated aggregation. Although curli fibres are not important for autoaggregation of E. coli cells grown to late exponential phase at $37^{\circ} \mathrm{C}$, curli expression is highly upregulated at lower temperatures (below $30^{\circ} \mathrm{C}$ ) and higher optical density (OD). Consistent with previous reports ${ }^{10,11}$, we observed that aggregation behaviour of cell grown at $30^{\circ} \mathrm{C}$ to $\mathrm{OD}_{600}=1.0$ was dependent on curli, whereas $f l u$ deletion had only a moderate effect (Fig. 6a and Supplementary Fig. 11a). Despite this different mode of cell-cell interaction and lower expression of $l s r$ operon at $30^{\circ} \mathrm{C}$ (Supplementary Fig. 12a), the dependence of curli-mediated aggregation on motility and AI-2 chemotaxis was similar to the Ag43-mediated aggregation. However, aggregates formed under these conditions showed little dispersal even after $3.5 \mathrm{~h}$ of observation (Supplementary Fig. 11b), presumably due to the lower rate of AI-2 accumulation at $30^{\circ} \mathrm{C}$ and/or higher stability of curli-mediated interactions. Consistently, biofilm formation at $30^{\circ} \mathrm{C}$ was affected by $c h e Y$ and $l s r B$ deletions, whereas $f l u$ deletion had lesser effect in this case (Fig. 6b), as confirmed by the crystal violet staining (Supplementary Fig. 12b) and quantification of the microcolony size distribution within biofilms (Supplementary Fig. 12c).

\section{Discussion}

The ability to form multicellular agglomerations, either suspended aggregates or surface-attached biofilms, is widespread among bacteria. Multicellular structures provide a number of benefits, such as increased resistance to various stress factors that are essential for bacterial survival under changing environmental conditions. Despite the importance of bacterial aggregation in the 
a

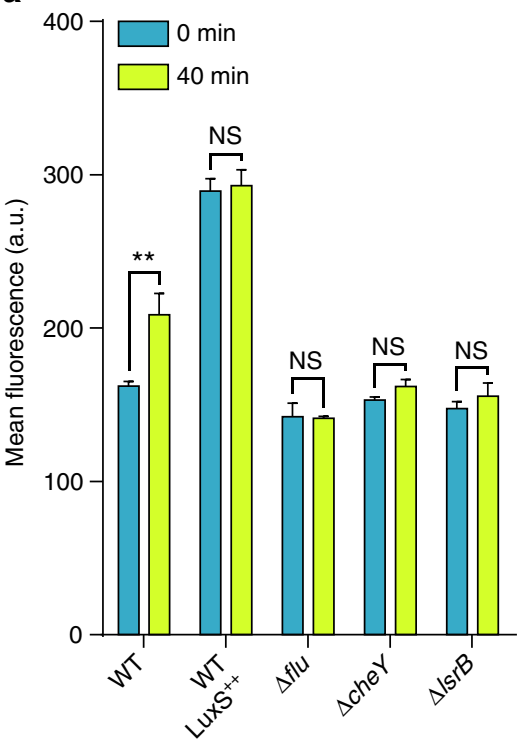

b
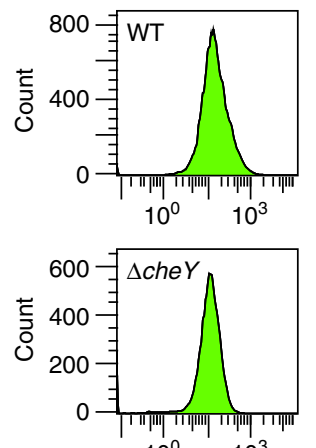

10

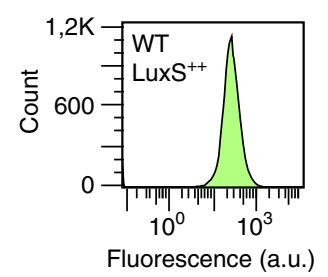

C
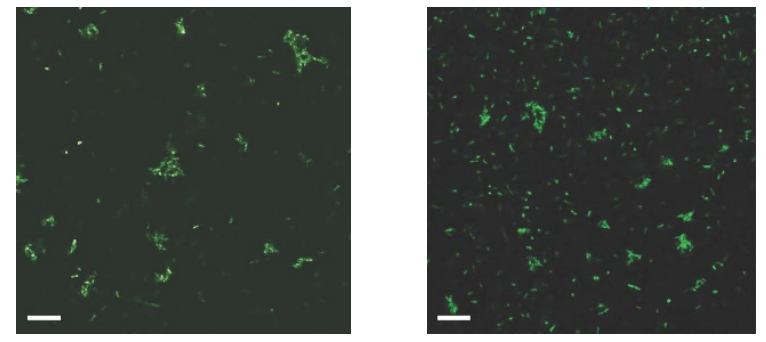

Ptrc-egfp
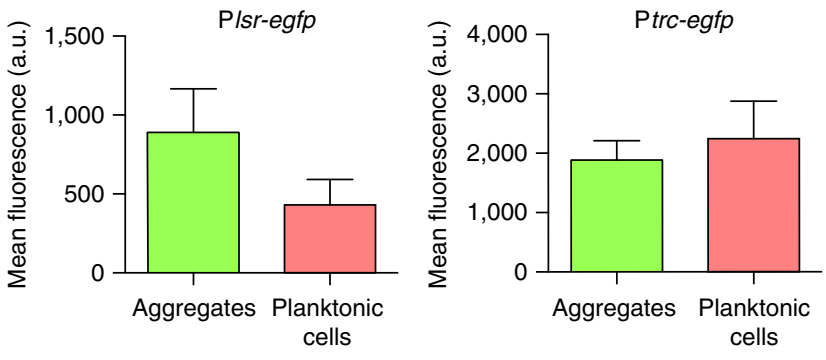

Figure 4 | High cell density in aggregates promotes induction of Al-2 response. (a) Isr promoter activation in the aggregating wild-type and non-

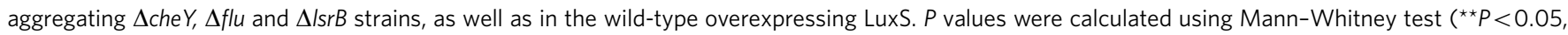
NS, not significant, $P>0.05$ ). (b) Distribution of fluorescence levels of $\mathrm{P}_{I s r}$-egfp at 40 min of aggregation in the wild type, $\Delta$ cheY (Mann-Whitney test, $P<0.05, n=3$ ) and in the wild-type overexpressing LuxS (Mann-Whitney test, $P<0.05, n=3$ ), measured using flow cytometry and expressed in arbitrary units (a.u.) of fluorescence. (c) Confocal microscopy images and corresponding quantification of $\mathrm{P}_{\text {Isr }}$-egfp fluorescence in aggregates and in planktonic cells

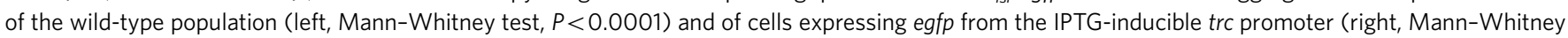
test, $P>0.05)$. Scale bars, $20 \mu \mathrm{m}$. Error bars in all panels indicate s.d. of three independent replicates.

environmental context, current understanding of this behaviour is still limited, even for such model organism as E. coli.

Flagellar motility and chemotaxis are normally associated with the behaviour of individual planktonic cells, and formation of biofilms is viewed as an irreversible transition from motile to the sessile lifestyle $1,33,34$. Although under some conditions flagella and motility are known to contribute to formation of surfaceassociated biofilms $\mathrm{s}^{35,36}$, these effects have been interpreted in the context of bacteria-surface interactions and not of cell-cell interactions. It was proposed that flagella may function as surface adhesins $^{37}$ or sensors ${ }^{38,39}$, or that swimming may promote transient cell-surface contacts ${ }^{40}$. The role of chemotaxis in biofilm formation has not been demonstrated to date, and $E$. coli chemotaxis mutants can form normal biofilms under standard conditions $^{32,35}$.

Even less explored are the functions of motility and chemotaxis in formation of suspended cell aggregates. In E. coli, autoaggregation was proposed to be mutually exclusive with motility ${ }^{4}$. In $A$. brasilense, aggregation (clumping) is affected by the deletion of Che1 chemotaxis pathway that modulates swimming velocity ${ }^{42}$, suggesting an important role for motility. However, the Che1mediated tactic response itself is not required for aggregation since deletion of the pathway increases rather than decreases clumping ${ }^{22}$.

Our study thus provides the first direct evidence that chemotaxis towards a self-secreted attractant mediates autoaggregation of bacteria. Notably, motility and chemotaxis are required regardless of the adhesin that mediates cell interactions in E. coli-Ag43 during exponential growth at $37^{\circ} \mathrm{C}$ or curli during early stationary phase at $30^{\circ} \mathrm{C}$. According to our observations, the aggregation process could be principally divided into three phases (Fig. 7). Phase I corresponds to the initial formation of 'seeding' aggregates by random collisions of motile cells, which does not require chemotaxis. Consistent with that, formation of small aggregates is observed for $\Delta c h e Y$ but not for
$\Delta f l i C$ or $\Delta m o t A$ cells (Fig. 1). At physiological cell densities, however, further growth of these aggregates through purely random collisions is relatively inefficient. Instead, during the next phase (phase II) these seeding aggregates apparently secrete sufficiently high levels of AI-2 to mediate gradient formation and chemotactic attraction of individual cells to the aggregates. Such chemoattraction greatly enhances the rate of aggregate growth, likely by increasing local cell density. Consistent with that, chemotaxis has a more pronounced effect on aggregation at lower densities of the cell culture (Fig. 1a,e and Supplementary Fig. 4). Chemoattraction results in a transient phase of rapid aggregate growth that subsequently slows down as the aggregates reach equilibrium with free-swimming cells, which is strongly shifted towards aggregates in the wild-type compared with nonchemotactic cells (Fig. 3). Subsequent gradual increase in the background levels of AI-2 in the medium disrupts chemotaxis towards aggregates, because cells are no longer able to follow gradients of AI-2 above high background, thus inducing aggregate dispersal (phase III). Supporting this explanation, during dispersal the levels of aggregation in the wild-type cells gradually approached those in the non-chemotactic or AI2-insensitive strains, whereas these latter strains showed no significant dispersal. Dispersal phase is particularly prominent for the Ag43-mediated aggregation, whereas curli-mediated interactions seem to be significantly more stable.

Aggregation mediated by the AI-2 taxis appears to have several physiological consequences. First, we observed that high local cell density within aggregates promotes AI-2 signalling in comparison with non-aggregating cells. E. coli can thus use autoaggregation to reach critical densities for quorum sensing already at low overall density of the population. Such local induction of quorumsensing response within aggregates is consistent with a theoretical concept of efficiency sensing ${ }^{43}$, as well as with a previously observed local quorum-sensing response induction in Vibrio harveyi ${ }^{21}$. 
a

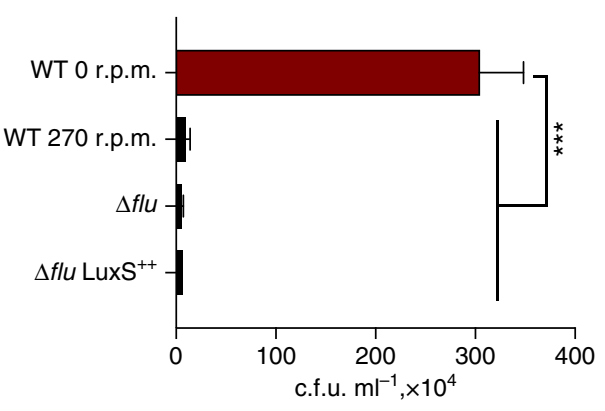

b

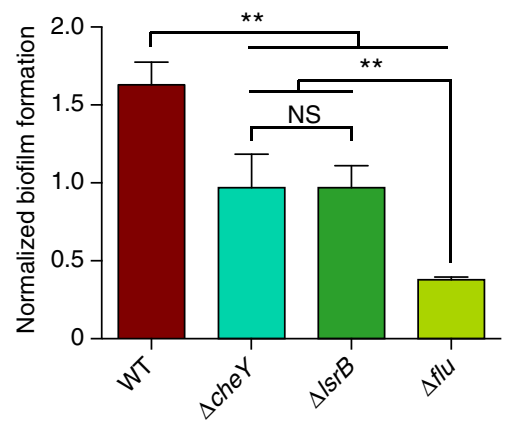

$\Delta$ cheY
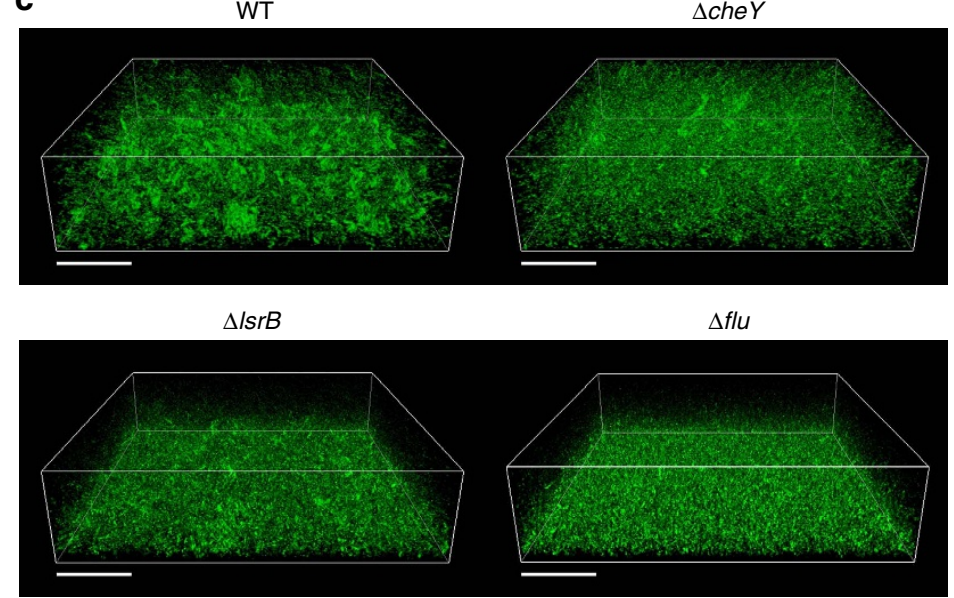

Figure 5 | Ag43-dependent aggregation promotes resistance to oxidative stress and biofilm formation. (a) Aggregation improves viability under oxidative stress conditions. Survival of the wild-type and $\Delta$ flu cells on exposure to $0.5 \% \mathrm{H}_{2} \mathrm{O}_{2}$ under aggregation (no shaking) or non-aggregation (shaking at 270 r.p.m.) conditions. Overexpression of LuxS does not rescue viability defect on the autoaggregation-defective $\Delta$ flu strain. $P$ value was calculated using Mann-Whitney test ( $\left.{ }^{\star \star} P<0.01\right)$. (b) Biofilm formation under static culture grown at $37^{\circ} \mathrm{C}$ for $24 \mathrm{~h}$, quantified using crystal violet (CV) staining. Shown in arbitrary units (a.u.) are CV values normalized by the optical density. $P$ values were calculated using Mann-Whitney test (**P<0.05, NS, not significant, $P>0.05$ ). Error bars in $\mathbf{a}, \mathbf{b}$ indicate s.d. of five independent replicates. (c) Confocal laser scanning microscopy of biofilms formed by the wild-type strain and by the aggregation-deficient mutants after $24 \mathrm{~h}$ static culture grown at $37^{\circ} \mathrm{C}$. Scale bars, $40 \mu \mathrm{m}$.

Although AI-2 is produced by many bacteria and is used for communication both within and between species, there are few characterized examples of physiological functions of AI-2 signalling ${ }^{25}$. Consequently, the importance of $E$. coli response to AI-2 beyond its uptake and metabolism remained unclear to date, although metabolism of AI-2 might itself provide bacteria with a benefit ${ }^{44}$ and/or with a competitive advantage in mixed communities ${ }^{45}$. Building on a previous observation ${ }^{27}$ of the chemotactic response to AI-2, here we characterized the first uptakeindependent function of AI-2 signalling in E. coli. Importantly, AI-2-mediated autoaggregation not only promotes local AI-2 signalling but it also provides physical protection against oxidative stress and contributes to the development of surfaceattached biofilms. Our results thus provide evidence for the longhypothesized role of self-attraction in cell aggregation and in biofilm formation. Given the ubiquitous nature of AI-2 production by bacteria, it is likely that chemotaxis to AI-2 is involved in aggregation, and possibly even co-aggregation, of other species.

\section{Methods}

Bacterial strains and growth conditions. The strains and plasmids used in this study are listed in Supplementary Table 1. All strains were derived from E. coli W3110 $\left(\mathrm{RpoS}^{+}\right)^{12}$. Cells were grown either on 1.5\% Luria Bertani (LB) agar or in liquid tryptone broth (TB) medium ( $10 \mathrm{~g}$ tryptone and $5 \mathrm{~g} \mathrm{NaCl}$ per litre) supplemented with antibiotics, where necessary. Gene deletions were obtained via
PCR-based inactivation of chromosomal genes ${ }^{46}$ or using P1 transduction ${ }^{47} \cdot \mathrm{Km}^{\mathrm{R}}$ cassettes were eliminated via FLP recombination ${ }^{48}$

To lock the ON state of Ag43 production, cells were transformed with a highcopy number plasmid (pVS1722) encoding Dam methyltransferase under control of a trc promoter inducible by isopropyl $\beta$-D-1-thiogalactopyranoside (IPTG). However, no induction was used, since the basal expression of Dam from pVS1722 was sufficient to abolish the Ag43 phase variation.

Autoaggregation assay. E. coli cells were grown overnight in TB with appropriate antibiotics at $37^{\circ} \mathrm{C}$ as indicated, diluted $1: 1,000$ and grown at $37^{\circ} \mathrm{C}$ with shaking at 200 r.p.m. to $\mathrm{OD}_{600}$ of $0.5-0.6$, unless stated otherwise. Where indicated, cells were alternatively grown at $30^{\circ} \mathrm{C}$ to $\mathrm{OD}_{600}$ of 1.0 . Cells were then collected by centrifugation ( $5 \mathrm{~min}, 4,700$ r.p.m.) and resuspended in $\mathrm{TB}$ to final $\mathrm{OD}_{600}$ of 1.0 (or 2.0 for cells with the native level of dam expression), unless stated otherwise. Cell suspensions were loaded into ibidi channels $\left(\mu\right.$-Slide Chemotaxis ${ }^{3 \mathrm{D}}$; ibidi $\mathrm{GmbH}$, Germany) and cell clumping was observed at room temperature $\left(20^{\circ} \mathrm{C}\right)$ using phase-contrast microscopy (Nikon TI Eclipse, $\times 10$ objective, numerical aperture $=0.3$, CMOS camera EoSens $4 \mathrm{CXP}$ ). Images were analysed using Particles Analysis Tool (ImageJ, http://imagej.nih.gov/ij/) to determine the area occupied by aggregates. Where indicated, synthetic DPD solution (provided by Dr Rita Ventura, ITQB, Oeiras, Portugal) ${ }^{49}$ was added to cell suspensions (because DPD spontaneously converts to AI-2, we referred to it as DPD/AI-2).

Aggregation kinetics was recorded at the final $\mathrm{OD}_{600}=0.5$ and at a frame rate of 0.5 frames per second. Image in each frame was corrected for the uneven illumination in the large field of view $(1.2 \times 0.72 \mathrm{~mm})$, using the Fit Polynomial filter of ImageJ to subtract the background approximated as a fourth-order polynomial. E coli cells and their aggregates were identified using a threshold ( -10 grey levels) relative to the evened background and analysed for their size using a custom-written particle-tracking algorithm. Aggregates were defined as objects with the size above $50 \mathrm{px}^{2}$, with single cells being on average $\sim 10 \mathrm{px}^{2}$. The exact value of the size threshold for aggregate assignment did not qualitatively affect the results. 
a

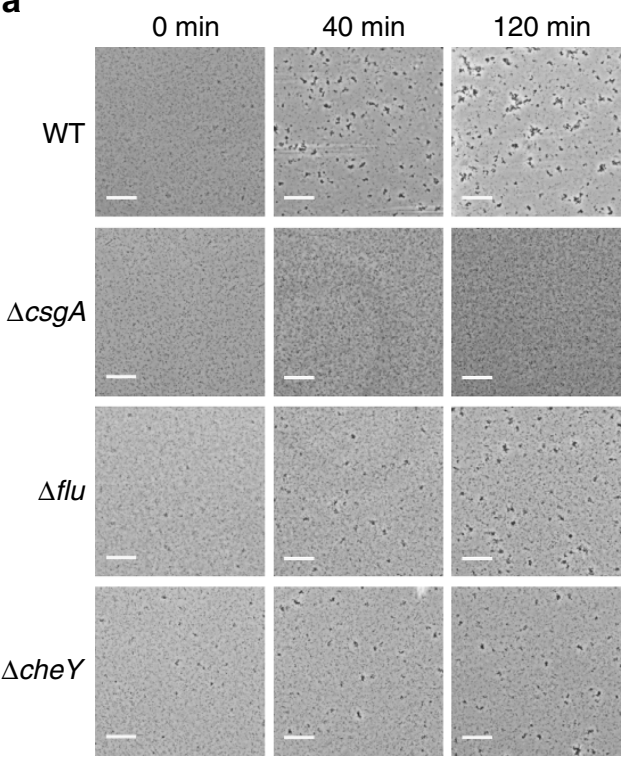

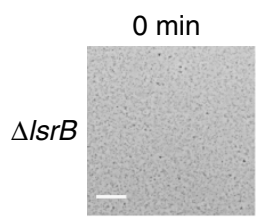
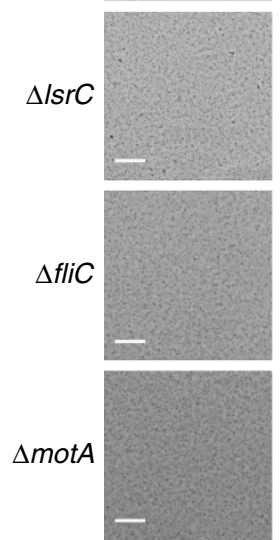

$40 \min$
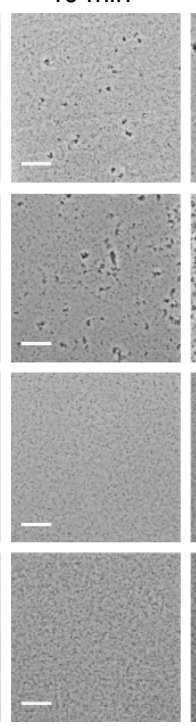

$\Delta c h e Y$
$120 \mathrm{~min}$
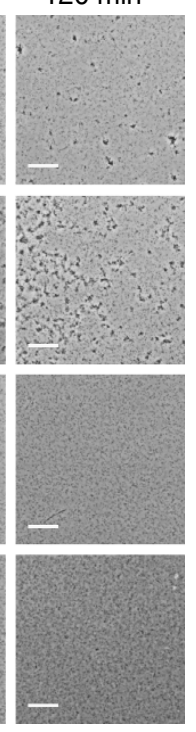

\section{b}

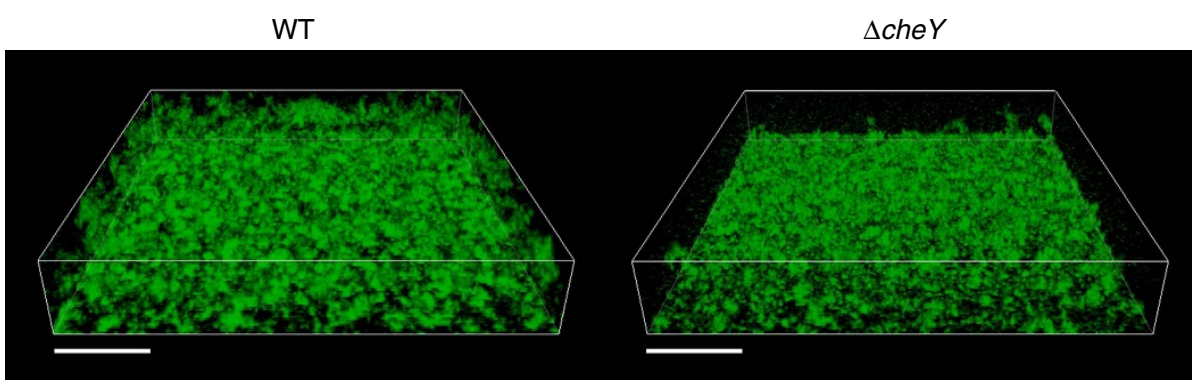

$\Delta / s r B$

$\Delta f l u$

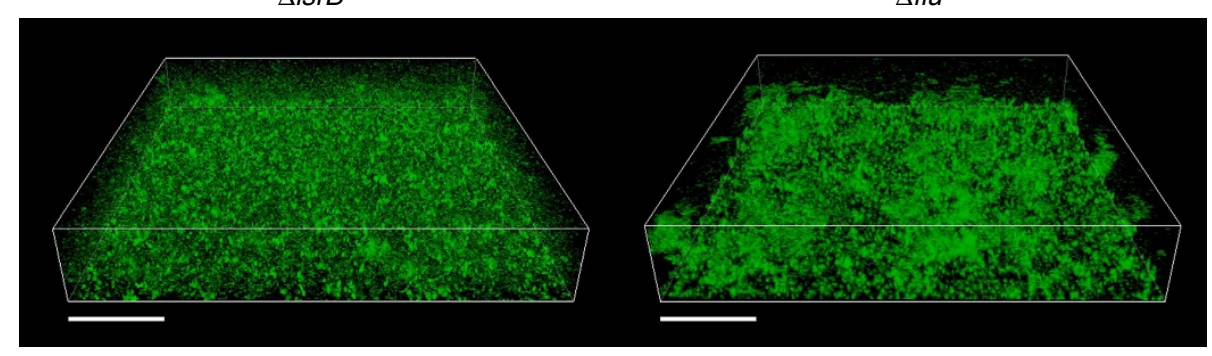

Figure 6 | Chemotaxis to Al-2 enhances curli-mediated aggregation and biofilm formation. (a) Aggregation of the wild-type E. coli W3110 cells and indicated knockout mutants grown to $\mathrm{OD}_{600}$ of 1.0 at $30^{\circ} \mathrm{C}$, and assayed as in Fig. 1 but at $\mathrm{OD}_{600}$ of 2.0. (b) Confocal laser scanning microscopy of biofilms formed at $30^{\circ} \mathrm{C}$ after $24 \mathrm{~h}$ static culture growth. In both experiments, cells with native level of Dam expression were used. Scale bars, $40 \mu \mathrm{m}$.

Immunodetection of Ag43. For the immunoblot analysis of Ag43 production ${ }^{23}$, cells were grown at $37^{\circ} \mathrm{C}$ to $\mathrm{OD}_{600}=0.6$ as described above, collected by centrifugation at 5,000 r.p.m. for $5 \mathrm{~min}$ and adjusted to the final $\mathrm{OD}_{600}$ of 1.0 . Samples $(100 \mu \mathrm{l})$ were separated using $10 \%$ SDS-polyacrylamide gel electrophoresis and transferred to the nitrocellulose membrane using western blotting. A polyclonal rabbit antiserum raised against the $\alpha$-domain of $\mathrm{Ag} 43$ (a gift of Dr Christophe Beloin, Institute Pasteur, Paris, France) was used at a dilution 1:10,000 for immunodetection of Ag43.

Hydrogen peroxide treatment. Cell survival on treatment with $\mathrm{H}_{2} \mathrm{O}_{2}$ was tested as described previously ${ }^{31}$. Briefly, cells were grown to $\mathrm{OD}_{600}$ of 0.6 as described above, washed once and resuspended in $\mathrm{TB}$ at final $\mathrm{OD}_{600}$ of 1.0 , and $100 \mu \mathrm{l}$ cell aliquots containing $\sim 10^{9}$ colony-forming units per ml were incubated for $1 \mathrm{~h}$ at room temperature in a microtitre plate. Subsequently $100 \mu \mathrm{l}$ of $1 \% \mathrm{H}_{2} \mathrm{O}_{2}$ was added to each sample, incubated for $15 \mathrm{~min}$ at room temperature, and cells were washed in $\mathrm{TB}$ and plated at appropriate dilutions to determine the number of surviving cells.

Flow cytometry. Activity of the $l s r$ promoter was assayed using a plasmid-based egfp reporter that contains the 217 nucleotide region upstream of the $l s r A$ gene.
Samples for flow cytometry were prepared as described above, diluted 1:20 in tethering buffer $\left(10 \mathrm{mM} \mathrm{KH}_{2} \mathrm{PO}_{4}, 100 \mu \mathrm{M}\right.$ EDTA, $1 \mu \mathrm{M}$ L-methionine and $10 \mathrm{mM}$ lactic acid, $\mathrm{pH}=7.0)$ and fluorescence was measured with BD LSRFortessa SORP cell analyser (BD Biosciences, Germany). Before the measurements, cell aggregates were dispersed by vigorous mixing.

The same reporter transformed in $\Delta l u x S$ strain was used as a biosensor to quantify levels of AI-2 in supernatants. Cell-free supernatants were prepared by filtration of liquid cultures through $0.2 \mu \mathrm{m}$ filter, and $20 \mu \mathrm{l}$ aliquots of the reporter strain $\left(\mathrm{OD}_{600}=0.5\right)$ were added to each sample followed by $40 \mathrm{~min}$ incubation at $37^{\circ} \mathrm{C}$. The reporter was calibrated using defined concentrations of synthetic DPD/AI-2.

Biofilm formation. Biofilm formation in polystyrene microtitre plates was tested using crystal violet staining assay ${ }^{50}$. Briefly, overnight cultures of samples were diluted in $\mathrm{TB}$ to $\mathrm{OD}_{600} 0.05$, and $300 \mu \mathrm{l}$ of each sample was added into the wells of 96-well plate (Corning Costar, flat bottom; Sigma-Aldrich, Germany). After $24 \mathrm{~h}$ of incubation at $37^{\circ} \mathrm{C}$, the $\mathrm{OD}_{600}$ of the samples was measured, the wells were rinsed with $\mathrm{H}_{2} \mathrm{O}$ and $300 \mu \mathrm{l}$ of $1 \%$ crystal violet solution was added to each well. After $15 \mathrm{~min}$ incubation at room temperature, the wells were rinsed three times with $\mathrm{H}_{2} \mathrm{O}$. Remaining crystal violet was solubilized by adding $300 \mu \mathrm{l}$ of $96 \%$ ethanol, and 


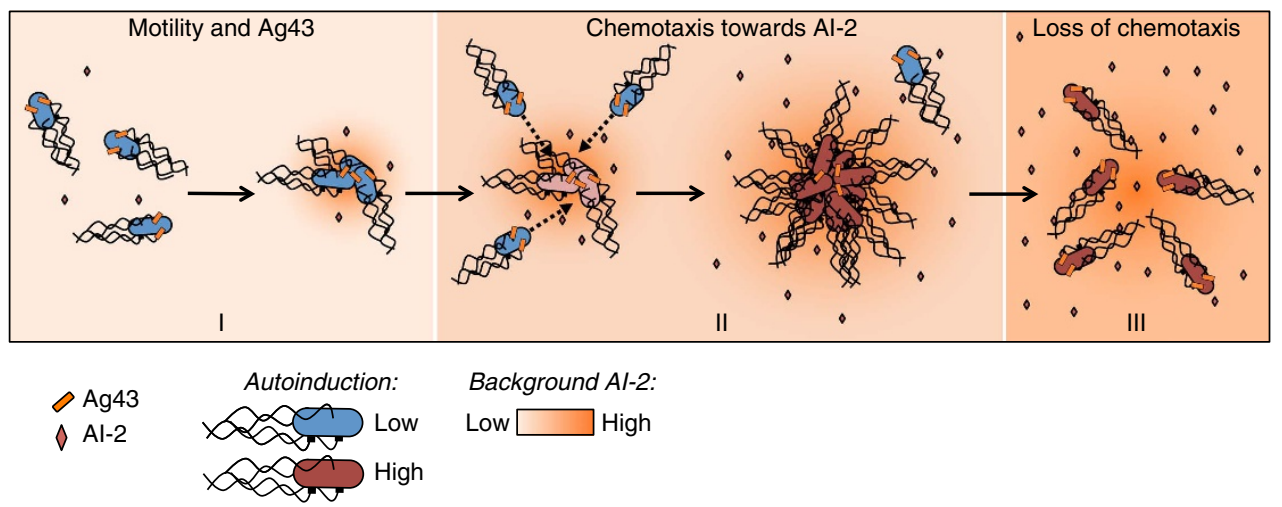

Figure 7 | Proposed model of autoaggregation. Ag43-mediated autoaggregation of $E$. coli can be schematically divided into three phases. Phase I corresponds to formation of initial 'seeding' aggregates by random collisions of Ag43-expressing motile cells. These initial aggregates subsequently grow during phase II. Here gradients of Al-2 that are produced by the aggregates serve to attract additional cells. Higher local cell density in the aggregates promotes Al-2-mediated autoinduction (de-repression of the Isr operon). Owing to relative weakness of Ag43-mediated interactions, a fraction of individual swimming cells remains at an equilibrium with the aggregates, and cells continue leaving and joining aggregates during this phase. Finally, phase III reflects dispersal of the aggregates. During this phase, increased levels of Al-2 in the culture lead to the loss of chemotaxis due to high background. This results in the subsequent gradual disaggregation, because more cells detach from aggregates than join them. Phases I and II are similar for curli-mediated aggregation, whereas phase III is less pronounced because of greater stability of interactions.

the $\mathrm{OD}_{595}$ of the solution was measured. Values of crystal violet staining were normalized for each sample by the respective $\mathrm{OD}_{600}$.

For biofilm imaging, overnight cultures carrying a high-copy number plasmid pVS1515 encoding egfp were diluted in $\mathrm{TB}$ to $\mathrm{OD}_{600} 0.05$ and grown with shaking at $30^{\circ} \mathrm{C}$ or $37^{\circ} \mathrm{C}$ to the mid-exponential phase $\left(\mathrm{OD}_{600}=0.6\right)$. The samples were then once again diluted in fresh TB containing $5 \mu \mathrm{M}$ IPTG to $\mathrm{OD}_{600}=0.05$, and $350 \mu \mathrm{l}$ of each sample was loaded into the wells of 8-well glass bottom slides ( $\mu$-Slide, 8-well glass bottom; ibidi). The cultures were grown at 30 and $37^{\circ} \mathrm{C}$ for $24 \mathrm{~h}$ without shaking.

Confocal laser scanning microscopy. The biofilm formation was visualized using Zeiss LSM-800 microscope equipped with Apochromat $\times 40$ objective. $Z$-stack image processing and analysis were performed using ZEN Black software (Zeiss). Quantification of microcolonies in mature biofilms was performed using 3D Objects Counter plugin for Image ${ }^{51}$, with Image segmentation threshold set to 30 .

Same set-up was used to quantify levels of $\mathrm{P}_{l s r}$-egfp expression in cell aggregates, prepared as described before. Images were analysed with ImageJ to evaluate the fluorescence intensity of the aggregates as well as of individual cells.

Chemotaxis assays. Chemotaxis assays were performed in microfluidic chemotaxis chambers ${ }^{52,53}$ that consisted of two reservoirs linked via a small channel with the length of $2 \mathrm{~mm}$ and width of $1 \mathrm{~mm}$ (Supplementary Fig. 6a), which was imprinted in a poly-di-methylsiloxane layer covalently bound to a microscopy glass slide. Cells were grown as described previously, washed thrice with motility buffer (MB; $10 \mathrm{mM} \mathrm{KPO}_{4}, 0.1 \mathrm{mM} \mathrm{EDTA}$ and $67 \mathrm{mM} \mathrm{NaCl}, \mathrm{pH}$ 7), and resuspended to a final $\mathrm{OD}_{600}=1$ in $\mathrm{MB}$ supplemented with $0.5 \%$ glucose (MBg). Cells were stored for $20 \mathrm{~min}$ in the fridge to reduce metabolic activity.

To measure chemotaxis towards synthetic DPD/AI-2, one of the reservoirs was filled with a cell suspension and the other with a MBg solution containing either 0 (negative control) or $10 \mu \mathrm{M} \mathrm{DPD} / \mathrm{AI}-2$. Where indicated, further $200 \mu \mathrm{M} \mathrm{DPD} /$ AI-2 was added to both reservoirs. No cells were added to the high-concentration reservoir, because DPD/AI-2 consumption by the cells could abolish the gradient. To test chemotaxis towards MeAsp in the presence of DPD/AI-2 (Supplementary Fig. 6a), the reservoirs were filled with cell suspensions containing $200 \mu \mathrm{M}$ background DPD/AI-2 and either 0 or $200 \mu \mathrm{M}$ of MeAsp. Since E. coli does not metabolize MeAsp, cells were added on both sides. As demonstrated previously ${ }^{52}$, diffusion of chemoattractants from the high-concentration reservoir through the channel creates a linear gradient of concentration within $1 \mathrm{~h}$.

The motion of the bacteria was observed using phase-contrast microscopy (magnification $\times 10$, numerical aperture $=0.3$ ) in the middle of the channel and recorded using a CMOS camera (Eosens $4 \mathrm{CXP}$ ) at 100 frames per second. The average swimming speed $\left(v_{0}\right)$ and the fraction of cells swimming $(\alpha)$ were determined using differential dynamic microscopy ${ }^{52}$. The average net drift of the population of cells $v_{\text {drift }}$ was measured using phase differential microscopy ${ }^{54}$. The chemotactic bias was defined as $b=v_{\text {driff }} / \alpha v_{0}$, which estimates the velocityindependent movement of the population of swimming cells in the gradient. In the case of diffusion alone, this bias can be estimated as $b_{\text {diff }}=l /(3(1-\cos \theta) L)$, where $l$ is the run length, $L$ the length of the channel and $\theta$ the average reorientation angle during tumbles ${ }^{55}$. In our case, we estimated $b_{\text {diff }} \sim 0.007$, with higher bias indicating attraction towards a chemical in the source reservoir.
Data availability. All the relevant data are available from the authors on request.

\section{References}

1. Hall-Stoodley, L., Costerton, J. \& Stoodley, P. Bacterial biofilms: from the natural environment to infectious diseases. Nat. Rev. Microbiol. 2, 95-108 (2004).

2. Klebensberger, J., Lautenschlager, K., Bressler, D., Wingender, J. \& Philipp, B. Detergent-induced cell aggregation in subpopulations of Pseudomonas aeruginosa as a preadaptive survival strategy. Environ. Microbiol. 9, 2247-2259 (2007).

3. Hasman, H., Chakraborty, T. \& Klemm, P. Antigen-43-mediated autoaggregation of Escherichia coli is blocked by fimbriation. J. Bacteriol. 181, 4834-4841 (1999).

4. van der Woude, M. W. \& Henderson, I. R. Regulation and function of Ag43 (flu). Annu. Rev. Microbiol. 62, 153-169 (2008).

5. Heras, B. et al. The antigen 43 structure reveals a molecular Velcro-like mechanism of autotransporter-mediated bacterial clumping. Proc. Natl Acad. Sci. USA 111, 457-462 (2014).

6. Schembri, M. A., Christiansen, G. \& Klemm, P. FimH-mediated autoaggregation of Escherichia coli. Mol. Microbiol. 41, 1419-1430 (2001)

7. Czeczulin, J. R. et al. Aggregative adherence fimbria II, a second fimbrial antigen mediating aggregative adherence in enteroaggregative Escherichia coli. Infect. Immun. 65, 4135-4145 (1997).

8. Bieber, D. et al. Type IV pili, transient bacterial aggregates, and virulence of enteropathogenic Escherichia coli. Science 280, 2114-2118 (1998).

9. Barnhart, M. M. \& Chapman, M. R. Curli biogenesis and function. Annu. Rev. Microbiol. 60, 131-147 (2006).

10. Römling, U., Rohde, M., Olsén, A., Normark, S. \& Reinköster, J. AgfD, the checkpoint of multicellular and aggregative behaviour in Salmonella typhimurium regulates at least two independent pathways. Mol. Microbiol. 36, 10-23 (2000).

11. Römling, U., Bian, Z., Hammar, M., Sierralta, W. D. \& Normark, S. Curli fibers are highly conserved between Salmonella typhimurium and Escherichia coli with respect to operon structure and regulation. J. Bacteriol. 180, 722-731 (1998).

12. Serra, D. O., Richter, A. M., Klauck, G., Mika, F. \& Hengge, R. Microanatomy at cellular resolution and spatial order of physiological differentiation in a bacterial biofilm. MBio 4, e00103-e00113 (2013).

13. Waldron, D. E., Owen, P. \& Dorman, C. J. Competitive interaction of the OxyR DNA-binding protein and the Dam methylase at the antigen 43 gene regulatory region in Escherichia coli. Mol. Microbiol. 44, 509-520 (2002).

14. Sourjik, V. \& Wingreen, N. S. Responding to chemical gradients: bacterial chemotaxis. Curr. Opin. Cell Biol. 24, 262-268 (2012).

15. Gerisch, G. Chemotaxis in Dictyostelium. Annu. Rev. 44, 535-552 (1982).

16. Alexandre, G. Chemotaxis control of transient cell aggregation. J. Bacteriol. 197, 3230-3237 (2015).

17. Park, S. et al. Influence of topology on bacterial social interaction. Proc. Natl Acad. Sci. USA 100, 13910-13915 (2003). 
18. Mittal, N., Budrene, E. O., Brenner, M. P. \& Van Oudenaarden, A. Motility of Escherichia coli cells in clusters formed by chemotactic aggregation. Proc. Natl Acad. Sci. USA 100, 13259-13263 (2003).

19. Budrene, E. O. \& Berg, H. C. Complex patterns formed by motile cells of Escherichia coli. Nature 349, 630-633 (1991).

20. Budrene, E. O. \& Berg, H. C. Dynamics of formation of symmetrical patterns by chemotactic bacteria. Nature 376, 49-53 (1995).

21. Park, S. et al. Motion to form a quorum. Science 301, 188 (2003).

22. Bible, A. N., Stephens, B. B., Ortega, D. R., Xie, Z. \& Alexandre, G. Function of a chemotaxis-like signal transduction pathway in modulating motility, cell clumping, and cell length in the alphaproteobacterium Azospirillum brasilense. J. Bacteriol. 190, 6365-6375 (2008).

23. Chauhan, A., Sakamoto, C., Ghigo, J. M. \& Beloin, C. Did I pick the right colony? Pitfalls in the study of regulation of the phase variable antigen 43 adhesin. PLoS ONE 8, e73568 (2013).

24. Li, M. \& Hazelbauer, G. L. Cellular stoichiometry of the components of the chemotaxis signaling complex. J. Bacteriol. 186, 3687-3694 (2004).

25. Pereira, C. S., Thompson, J. A. \& Xavier, K. B. AI-2-mediated signalling in bacteria. FEMS Microbiol. Rev. 37, 156-181 (2013).

26. Miller, S. T. et al. Salmonella typhimurium recognizes a chemically distinct form of the bacterial quorum-sensing signal AI-2. Mol. Cell 15, 677-687 (2004).

27. Hegde, M. et al. Chemotaxis to the quorum-sensing signal AI-2 requires the Tsr chemoreceptor and the periplasmic LsrB AI-2-binding protein. J. Bacteriol. 193, 768-773 (2011).

28. Neumann, S., Hansen, C. H., Wingreen, N. S. \& Sourjik, V. Differences in signalling by directly and indirectly binding ligands in bacterial chemotaxis. EMBO J. 29, 3484-3495 (2010).

29. Neumann, S., Vladimirov, N., Krembel, A. K., Wingreen, N. S. \& Sourjik, V. Imprecision of adaptation in Escherichia coli chemotaxis. PLOS ONE 9, e84904 (2014).

30. Berg, H. C. \& Tedesco, P. M. Transient response to chemotactic stimuli in Escherichia coli. Proc. Natl Acad. Sci. USA 72, 3235-3239 (1975).

31. Schembri, M. A., Hjerrild, L., Gjermansen, M. \& Klemm, P. Differential expression of the Escherichia coli autoaggregation factor antigen 43. J. Bacteriol. 185, 2236-2242 (2003).

32. Danese, P. N., Pratt, L. A., Dove, S. L. \& Kolter, R. The outer membrane protein, antigen 43, mediates cell-to-cell interactions within Escherichia coli biofilms. Mol. Microbiol. 37, 424-432 (2000).

33. Beloin, C., Roux, A. \& Ghigo, J. M. Escherichia coli biofilms. Curr. Top. Microbiol. Immunol. 322, 249-289 (2008).

34. Guttenplan, S. B. \& Kearns, D. B. Regulation of flagellar motility during biofilm formation. FEMS Microbiol. Rev. 37, 849-871 (2013).

35. Pratt, L. A. \& Kolter, R. Genetic analysis of Escherichia coli biofilm formation: roles of flagella, motility, chemotaxis and type I pili. Mol. Microbiol. 30, 285-293 (1998).

36. Houry, A., Briandet, R., Aymerlch, S. \& Gohar, M. Involvement of motility and flagella in Bacillus cereus biofilm formation. Microbiology 156, 1009-1018 (2010).

37. Haiko, J. \& Westerlund-Wikström, B. The role of the bacterial flagellum in adhesion and virulence. Biology (Basel) 2, 1242-1267 (2013).

38. Belas, R. Biofilms, flagella, and mechanosensing of surfaces by bacteria. Trends Microbiol. 22, 517-527 (2014).

39. Cairns, L. S., Marlow, V. L., Bissett, E., Ostrowski, A. \& Stanley-Wall, N. R. A mechanical signal transmitted by the flagellum controls signalling in Bacillus subtilis. Mol. Microbiol. 90, 6-21 (2013).

40. Conrad, J. C. Physics of bacterial near-surface motility using flagella and type IV pili: implications for biofilm formation. Res. Microbiol. 163, 619-629 (2012).

41. Ulett, G. C., Webb, R. I. \& Schembri, M. A. Antigen-43-mediated autoaggregation impairs motility in Escherichia coli. Microbiology 152, 2101-2110 (2006)

42. Bible, A., Russell, M. H. \& Alexandre, G. The Azospirillum brasilense Che1 chemotaxis pathway controls swimming velocity, which affects transient cellto-cell clumping. J. Bacteriol. 194, 3343-3355 (2012).

43. Hense, B. A. et al. Does efficiency sensing unify diffusion and quorum sensing? Nat. Rev. Microbiol. 5, 230-239 (2007).
44. Marques, J. C. et al. LsrF, a coenzyme A-dependent thiolase, catalyzes the terminal step in processing the quorum sensing signal autoinducer-2. Proc. Natl Acad. Sci. USA 111, 14235-14240 (2014).

45. Xavier, K. B. \& Bassler, B. L. Interference with AI-2-mediated bacterial cell-cell communication. Nature 437, 750-753 (2005).

46. Datsenko, K. A. \& Wanner, B. L. One-step inactivation of chromosomal genes in Escherichia coli K-12 using PCR products. Proc. Natl Acad. Sci. USA 97, 6640-6645 (2000).

47. Miller, J. H. Experiments in Molecular Genetics (Cold Spring Harbor Laboratory, 1972).

48. Cherepanov, P. P. \& Wackernagel, W. Gene disruption in Escherichia coli: TcR and $\mathrm{KmR}$ cassettes with the option of Flp-catalyzed excision of the antibioticresistance determinant. Gene 158, 9-14 (1995).

49. Ascenso, O. S. et al. An efficient synthesis of the precursor of AI-2, the signalling molecule for inter-species quorum sensing. Bioorg. Med. Chem. 19, 1236-1241 (2011).

50. Genevaux, P., Muller, S. \& Bauda, P. A rapid screening procedure to identify mini-Tn10 insertion mutants of Escherichia coli $\mathrm{K}-12$ with altered adhesion properties. FEMS Microbiol. Lett. 142, 27-30 (1996).

51. Bolte, S. \& Cordelières, F. P. A guided tour into subcellular colocalization analysis in light microscopy. J. Microsc. 224, 213-232 (2006).

52. Wilson, L. G. et al. Differential dynamic microscopy of bacterial motility. Phys Rev. Lett. 106, 018101 (2011).

53. Krembel, A., Colin, R. \& Sourjik, V. Importance of multiple methylation sites in Escherichia coli chemotaxis. PLoS ONE 10, e0145582 (2015).

54. Colin, R., Zhang, R. \& Wilson, L. G. Fast, high-throughput measurement of collective behaviour in a bacterial population. J. R. Soc. Interface 11, 20140486 (2014).

55. Lovely, P. S. \& Dahlquist, F. W. Statistical measures of bacterial motility and chemotaxis. J. Theor. Biol. 50, 477-496 (1975).

\section{Acknowledgements}

We thank Olga Besharova, Verena Suchanek and Aleksandra Kolodziejczyk for providing strains and plasmids; Dr Christophe Beloin for providing Ag43 antibodies; and Dr Ned S. Wingreen for discussions. This work was supported by grant 294761-MicRobE from the European Research Council, grant R01 GM082938 from the National Institutes of Health and grants SO 421/11-1 and SO 421/12-1 from the Deutsche Forschungsgemeinschaft.

\section{Author contributions}

L.L., R.C. and V.S. designed the experiments; L.L. and R.C. performed the experiments. All authors analysed the data and wrote the manuscript.

\section{Additional information}

Supplementary Information accompanies this paper at http://www.nature.com/ naturecommunications

Competing financial interests: The authors declare no competing financial interests.

Reprints and permission information is available online at http://npg.nature.com/ reprintsandpermissions/

How to cite this article: Laganenka, L. et al. Chemotaxis towards autoinducer 2 mediates autoaggregation in Escherichia coli. Nat. Commun. 7, 12984 doi: 10.1038/ncomms12984 (2016).

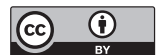

This work is licensed under a Creative Commons Attribution 4.0 International License. The images or other third party material in this article are included in the article's Creative Commons license, unless indicated otherwise in the credit line; if the material is not included under the Creative Commons license, users will need to obtain permission from the license holder to reproduce the material. To view a copy of this license, visit http://creativecommons.org/licenses/by/4.0/

(C) The Author(s) 2016 


\title{
Corrigendum: Chemotaxis towards autoinducer 2 mediates autoaggregation in Escherichia coli
}

\author{
Leanid Laganenka, Remy Colin \& Victor Sourjik
}

Nature Communications 7:12984 doi: 10.1038/ncomms12984 (2016); Published 30 Sep 2016; Updated 15 Dec 2016

Two previous studies describing the effects of autoinducer 2 (AI-2) on biofilm formation and chemotaxis in Escherichia coli were inadvertently omitted from the reference list of this Article. A reference to these studies along with ref. 27 should have been provided in the Introduction, as follows: 'It has been previously reported that, in E. coli, AI-2 can modulate biofilm formation (González-Barrios et al. 2006) and virulence-related phenotypes such as chemotaxis, swimming motility and attachment to host cells in vitro (Bansal et al. 2008, ref. 27).' These findings should have also been mentioned in the Abstract, where the physiological role of AI-2 in E. coli and other bacteria is referred to, and in the sections discussing motility, chemotaxis and biofilm formation in E. coli.

González Barrios, A. F. et al. Autoinducer 2 controls biofilm formation in Escherichia coli through a novel motility quorum-sensing regulator (MqsR, B3022). J. Bacteriol. 188, 305-316 (2006).

Bansal, T., Jesudhasan, P., Pillai, S., Wood, T. K. \& Jayaraman, A. Temporal regulation of enterohemorrhagic Escherichia coli virulence mediated by autoinducer-2. Appl. Microbiol. Biotechnol. 78, 811-819 (2008).

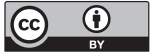

This work is licensed under a Creative Commons Attribution 4.0 International License. The images or other third party material in this article are included in the article's Creative Commons license, unless indicated otherwise in the credit line; if the material is not included under the Creative Commons license, users will need to obtain permission from the license holder to reproduce the material. To view a copy of this license, visit http://creativecommons.org/licenses/by/4.0/

(C) The Author(s) 2016 